\title{
Expansão de Sinop e o mercado imobiliário.
}

Expansion of Sinop and the real estate market.

Expansión de Sinop y el mercado inmobiliario.

Guilherme Rosa de Almeida

Professor Mestre, UNIVAG, Brasil guilherme.almeida@univag.edu.br

Kamila Bordulis Damo Estudante de Arquitetura e Urbanismo, UNIVAG, Brasil. kamila_damo@hotmail.com 


\section{RESUMO}

A configuração socioespacial da cidade de Sinop e como agem os agentes produtores do espaço, em especial os incorporadores e imobiliárias é foco de nosso estudo neste artigo. A cidade foi planejada nos anos 70 do século XX como parte do plano de ocupação das terras da Amazônia legal. Sendo desde o início pensada como polo regional e destinada a atender as funções do agronegócio. Aqui debateremos como esta cidade, de menos de 45 anos, se expande por um grande área e passa a contar com áreas valorizadas, fonte de especulação urbana bem como regiões com falta de infraestrutura e destinadas a população sem poder aquisitivo. Investigamos como a cidade tem se expandido em direção a novos vetores, contrariando o plano original de implantação.

PALAVRAS-CHAVE: Sinop, Segregação Socioespacial, Imobiliárias.

\section{ABSTRACT}

The socio-spatial configuration of the city of Sinop and how space-producing agents act, especially developers and real estate agents, is the focus of our study in this article. The city was planned in the 70's of the twentieth century as part of the legal occupation of the land of the Amazon. Being from the beginning thought as a regional hub and intended to serve the functions of agribusiness. Here we will discuss how this city, less than 45 years, expands by a great area and happens to have areas valued, source of urban speculation as well as regions with lack of infrastructure and destined to the population without purchasing power. We investigate how the city has expanded to new vectors, contrary to the original implantation plan.

KEY WORDS: Sinop, Socio-spatial segregation, real estate agencies.

\section{RESUMEN}

La configuración socioespacial de la ciudad de Sinop y cómo actúan los agentes productores del espacio, en especial los incorporadores e inmobiliarias es foco de nuestro estudio en este artículo. La ciudad fue planeada en los años 70 del siglo XX como parte del plan de ocupación de las tierras de la Amazonia legal. Siendo desde el principio pensada como polo regional y destinada a atender las funciones del agronegocio. Aquí debatiremos cómo esta ciudad, de menos de 45 años, se expande por un gran área y pasa a contar con áreas valoradas, fuente de especulación urbana así como regiones con falta de infraestructura y destinadas a la población sin poder adquisitivo. Investigamos cómo la ciudad se ha expandido hacia nuevos vectores, contrariando el plan original de implantación.

PALABRAS CLAVE: Sinop, Segregación Socioespacial, Inmobiliarias. 


\section{INTRODUÇÃO}

Este trabalho é resultado parcial de uma pesquisa sobre a cidade de Sinop consequência das pesquisas desenvolvidas no Centro Universitário de Várzea Grande (UNIVAG) sobre as cidades mato-grossenses e o setor imobiliário. Destacaremos com especial atenção a sua estrutura fundiária e o papel das imobiliárias na configuração e expansão da cidade.

O plano de ocupação desta porção do território brasileiro consolida-se através de uma geopolítica defendida pela Escola Superior de Guerra no período da ditadura militar (19641985). Embora desde os tempos coloniais existiram planos de ocupação de áreas na região oeste e amazônica do país, como podemos citar a cidade de Vila Bela da Santíssima Trindade (MT) e a construções de fortes como Príncipe da Beira em Rondônia, entre outras. A efetiva ocupação destas regiões se dá a partir do fim anos 60 e início dos anos 70 do século XX.

Sinop e outras cidades as margens da BR-163, como Sorriso e Lucas do Rio Verde são cidades que surgiram no processo de ocupação das terras amazônicas, tendo suporte na infraestrutura empreendida que uniu o poder público, empresários e colonos para esta tarefa. Sinop tem sua ocupação a partir de 1972 sempre possuindo grande dinamismo econômico e destacando-se como polo regional. Uma de suas características marcantes é o papel que desde sua origem exerce o setor incorporador e imobiliário privado como agente modelador do espaço urbano e de sua estrutura fundiária.

O Programa de Integração Nacional - PIN, dos anos 70 do século XX, destinou um conjunto de incentivos fiscais e financeiros para região amazônica, a partir da atuação da Superintendência de Desenvolvimento da Amazônia (SUDAM) e da Superintendência de Desenvolvimento do Centro-Oeste (SUDECO). Desta forma o município mato-grossense de Sinop é um retrato do uso dos fundos públicos e territoriais e do deslocamento da força de trabalho ${ }^{1}$ no desenvolvimento regional brasileiro. Segundo Joanoni Neto (2007, p. 78 apud SILVA, 2015. p.12-13), para colonização o alvo foi o sul do Brasil:

A região Sul do Brasil foi escolhida como alvo da propaganda, pois ali existia grande número de pessoas que havia realizado acumulação de capital e aquelas áreas, principalmente a do Paraná, estavam supervalorizadas, daí tais colonos terem sido considerados ideais. Eles foram forçados ou induzidos a se deslocarem-se para o território mato-grossense, onde se utilizaram da experiência já adquirida para abrir a nova área.

A ocupação destas terras reuniu diversos e diferentes requisitos que se somam entre eles: a expansão do capital internacional em busca de terras para commodities, os conflitos de terras

\footnotetext{
${ }^{1}$ Este processo de intensa migração interna é interessante e complexo. Tanto no que tange a cultura introduzida pelos colonos de diferentes regiões, em especial do sul do país, quanto pela dinâmica de sucessos e fracassos nesta empreitada que dependeu muito das articulações entre poder público e privado, acessos a privilégios de uns e de dificuldades de acessos a incentivos de outros.
} 
pelo Brasil, principalmente na região sul, o que pressionava o governo federal por repostas em nome de uma possível reforma agrária e o desenvolvimento tecnológico a nível de mudanças profundas no solo, nas sementes e no maquinário, o interesse dos planos geopolíticos de ocupação da terras amazônicas. São todos importantes condicionantes históricos materiais para compreendermos o clima que existente no período e que permitiu esta empreitada de colonização desta região do Brasil.

Harvey (2005) cita algumas relações de transformação do espaço técnico-informacional, ao analisar a produção do espaço pelo capital, que coloca em evidência condições que permitiram a ocupação do território norte mato-grossense:

A racionalização geográfica do processo produtivo depende, em parte, da estrutura mutável dos recursos de transporte, das matérias-primas e das demandas do mercado em relação à indústria, e da tendência inerente à aglomeração e à concentração da parte do próprio capital. No entanto, essa tendência exige, para sustentá-la, a inovação tecnológica. (HARVEY.2005, p.52)

Estes objetivos foram estrategicamente alcançados através de diversos planos estabelecidos pelo governo federal de incentivos, das mudanças tecnológicas que permitiram as terras do cerrado se tornarem atraentes e da propaganda em massa para atrair colonos

O slogan "integrar para não entregar" que fazia parte do Programa de Integração Nacional, também financiou obras de infraestrutura e aberturas de rodovias federais. Implantando as seguintes rodovias: BR 163, Cuiabá - Santarém, BR 364, Cuiabá - Porto Velho, BR 070, Rio Araguaia - Cuiabá, BR 080 Rio Araguaia - Cachimbo, BR 168, Barra do Garças - São Félix do Araguaia e a BR 174, Cáceres até a Rondônia. (MOURA, 2013.p. 18).

A extensão da BR 163 de Cuiabá a Santarém² permitiu uma articulação de interesses entre a empresa Sociedade Imobiliária Noroeste do Paraná (SINOP), ${ }^{3}$ e o governo militar que concede a preços e condições excepcionais para esta empresa adquira uma área de terras localizada a $500 \mathrm{~km}$ ao norte de Cuiabá, chamada na época de Gleba Celeste, com o objetivo de implantar seus projetos de colonização, que incluíram outros municípios além de Sinop. Como Santa Carmem e Vera, estas fora do eixo da BR 163, Sinop escolhida como polo no eixo da rodovia que teve seu traçado alterado várias vezes até a execução final. A ocupação da Gleba começa em 1972 com a chega de colonos, o distrito de Sinop é criado em 1976, subordinado ao município de Chapada dos Guimarães, em 1979 é elevado à categoria de município. A figura 1 abaixo indica a localização da cidade no contexto nacional e regional.

Mato Grosso é um Estado que tem sua economia ao redor do setor agrícola. Onde a maior parte de suas cidades, 141 municípios no total, foram criados nos últimos 45 anos. São cidade novas que fazem parte de um processo de apoio às atividades rurais, são pontos condensados de vida

\footnotetext{
${ }^{2}$ Ainda inconclusa, existem cerca de $190 \mathrm{Km}$ não pavimentados entre Sinop e Santarém.

${ }^{3}$ De onde origina-se o nome da cidade.
} 
Revista Nacional de Gerenciamento de Cidades

urbana, que servem ao interesse agroindustrial. Algumas cidades possuem acesso facilitado pelas rodovias como Sinop, outras cidades estão situadas em locais distantes e de difícil acesso e, às vezes, sem articulação no contexto regional, como várias cidades na região do Araguaia. 0 que faz com que as atividades agrícola e exportadora da economia estadual sejam concentradas em poucos polos.

Figura 1: Localização de Sinop.

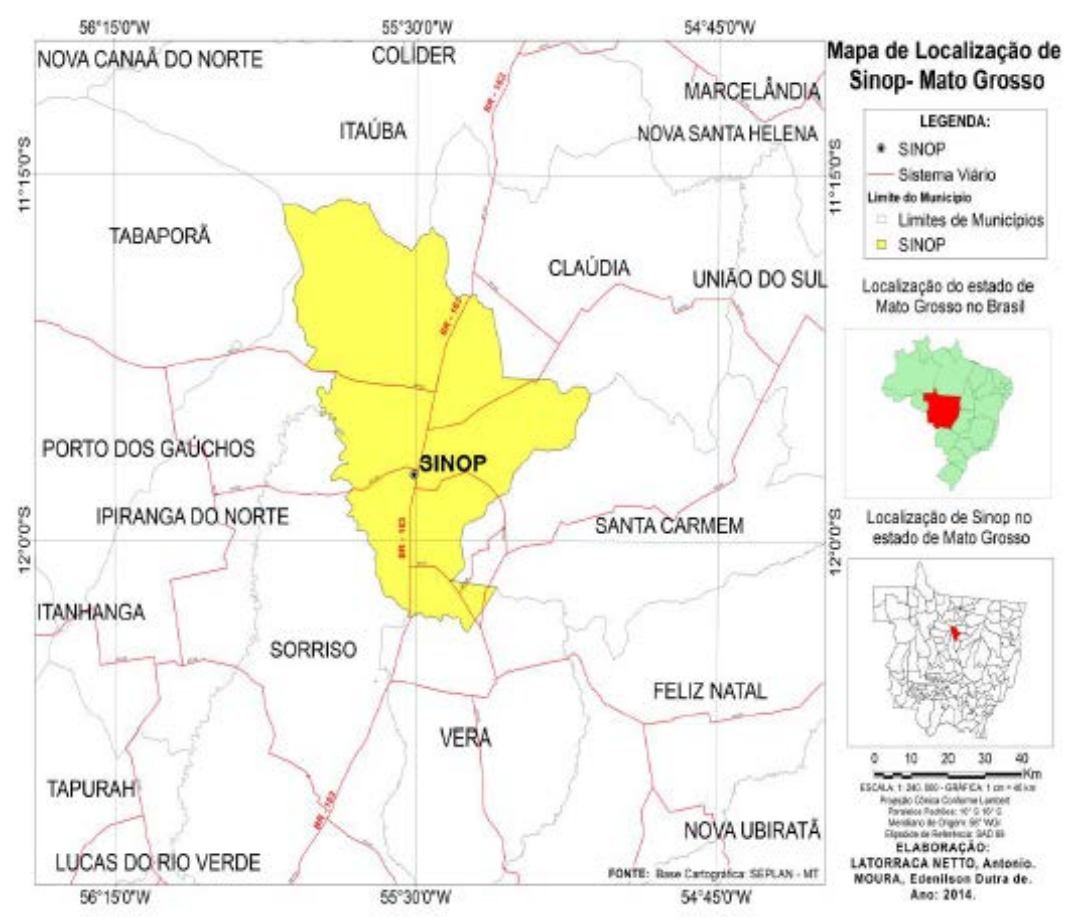

Fonte: SEPLAN, 2010. Modificado por LATORRACA NETTO e MOURA (2014)

\section{OBJETIVOS}

Analisar a configuração socioespacial e como atuam os agentes produtores do espaço. Tendo no setor imobiliário um importante agente, pois tem se mostrado predominante no desenvolvimento urbano da cidade, desde seu plano de ocupação até os dias atuais. A questão da localização das habitações em relação ao acesso a infraestrutura e demais equipamentos urbanos, traçando uma relação entre a segregação gerada pelo mercado formal e seus preços.

\section{METODOLOGIA}

Temos na geografia crítica, articulada com uma perspectiva econômica, como fonte para nossas pesquisas e compreensão de mundo. Entendendo com isso que as Ciências Humanas e Sociais tem um propósito interpretativo do mundo, visando com isso a compreensão da sociedade e da 
cultura. Apresentando como técnicas metodológicas na pesquisa o estudo da bibliografia especializada, dados sobre o município, as legislações municipais, a consulta as produções publicitárias do setor imobiliário, visita de campo e entrevistas in loco e a distância.

\section{RESULTADOS}

A cidade é construída de modo tão peculiar que uma pessoa pode morar nela durante anos e anos, ir e vir todos os dias e nunca passar perto de um bairro operário ou mesmo de operários... (ENGELS apud NESBITT. 2008. p 416).

Sempre que se ocupa o espaço, que se edifica é para alguém, com recursos de alguém e para determinadas finalidades e interesses. É no processo de transformação solo em glebas, as glebas em lotes, os lotes em mercadoria cobiçada que vivem as imobiliárias e incorporadoras. Os custos da infraestrutura são sempre socializados, pagos por todos os seus habitantes, agora sua apropriação não, pois o lucro fica nas mãos das empresas empreendedoras desses serviços e dos proprietários dos terrenos, que se beneficiam com vantagens advindas da valorização das áreas contempladas. Seja por infraestrutura básica como pavimentação, águas pluviais, etc. Ou pela instalação de centros universitários, centro de pesquisa, aeroportos, etc. Todos estes empreendimentos valorizam o solo e seus arredores.

Estes locais com infraestrutura, acabam se tornando inacessível para boa parte da população que sem recursos para comprar lotes, vão para ocupações irregulares. Nesse quadro de desigualdade no acesso, desempenham papéis predominantes o estado (ação ou omissão) e as incorporadoras e imobiliárias. Processo de gentrificação e exclusão socioespacial.

Apoiadas na estrutura fundiária rural e urbana complexa e excludente, que permite a expansão urbana em solo rural a custos mínimos para os investidores e com retornos privados imensos, os planos diretores coletivos desaparecem neste momento. Segundo Carlos:

Assim, o espaço-mercadoria se propõe para a sociedade como valor de troca, destituído de seu valor de uso e, nessa condição e meio da realização da vida social, às necessidades da reprodução da acumulação como imposição para a reprodução social. (CARLOS, 2011. p.62)

A estrutura fundiária está relacionada ao acesso à terra, ao solo, ou seja a primeira condição para habitação e produção autônoma. Aqui o foco é estrutura fundiária urbana que sem dúvidas está intimamente relacionada a agrária, ainda mais numa cidade com economia agroindustrial. Neste caso a terra teve um único proprietário no início a Colonizadora SINOP, uma concentração absoluta de poder e renda. Conhecer como este espaço urbano foi e é loteado configurando o 
espaço da cidade nos auxilia a entender a lógica que existe no lugar. Nas palavras de Rossi ao tratar do tema fundiário:

A forma dos lotes na cidade, formação, sua evolução, representa a longa história da propriedade urbana e a história das classes profundamente ligadas à cidade. Disse Tricart, muito lucidamente, que a análise do contraste no desenho dos lotes confirma a existência da luta de classes. A modificação da estrutura fundiária urbana que podemos seguir com absoluta precisão através dos mapas cadastrais históricos indica o surgimento da burguesia urbana e o fenômeno da concentração progressiva do capital. (2001, p.36).

Ao buscarmos analisar na cidade de Sinop como os incorporadores, imobiliárias e poder público e a população ocupam efetivamente a cidade, seguindo planos ou não queremos entender como se dá este processo de acumulação ou distribuição do direito à cidade. Este que passa tanto pela infraestrutura a urbana, como do acesso ao lotes. Quem tem acesso? Onde estão localizados estes loteamentos? Quais fatores estão agindo para cidade crescer desta forma? São questões que envolvem múltiplos agentes e condicionantes.

Estamos cientes de que o espaço registra e materializa a forma de produção capitalista na qual vivemos. As consequências do nosso modelo de produção econômico estão presentes na estrutura fundiária e que se apresenta a nossos olhos de muitas formas entre elas: a fragmentação do espaço, os conflitos, as pressões políticas por privilégios, etc. Ao tratar da relação espaço-capital Moreira traz:

O que afirmamos, então, é que o arranjo espacial brota tanto do processo de produção e distribuição, quanto do controle que se exerce sobre as relações existentes entre as classes. Como o processo de produção-distribuição se faz sob o condicionamento das formas como se travam as relações entre as classes, pode-se afirmar que o arranjo espacial, na verdade, numa sociedade de classes, reproduz em síntese as relações de classes da formação econômico-social. (MOREIRA, 1982 p.3)

O projeto inicial de Sinop ${ }^{4}$ concebido pela colonizadora, mirava a implantação de um município com foco no setor agropecuário. O mapa elaborado quando de sua criação, previa um cinturão verde de chácaras em volta do núcleo urbano afim de produzir alimentos para a população local. Contudo os planos de produção em larga escala de café não foram bem sucedidos e outras soluções econômicas foram sendo implantadas como a extração de madeira. Até que com as

\footnotetext{
${ }^{4}$ Alguns municípios em MT "brigam" pelo título de capital do agronegócio, Sinop, Cuiabá e Sorriso este contando com bolsa de valores BMF de commodities diretamente ligada com a bolsa do setor em Chicago.
} 
modificações realizadas no solo e técnicas permitiu-se a plantação de soja e outros produtos agrícolas com valor de exportação.

A cidade conta com serviços na área de educação, saúde, instituições públicas e privadas para região. Possui implantados e com ensino superior presencial através das Instituições seguintes: Universidade de Cuiabá: Campus Industrial e Campus Aeroporto (UNIC), Faculdade de Sinop (FASIPE), Universidade Federal de Mato Grosso (UFMT), Universidade do Estado de Mato Grosso (UNEMAT). Hospital Regional público e dois hospitais particulares. Instaladas grandes armazéns de empresas multinacionais como Bunge, ADM, Cargil, Friagril. Sendo considerada polo regional para cerca de 30 cidades.

O plano urbanístico da cidade foi penado dentro de um rigoroso traçado geométrico, a proposta acabou não sendo seguida à risca, pois os rumos que os agentes produtores do espaço como bem fala Côrrea Lobato (1995), nunca são simples. A realidade material é sempre mais complexa que os planos urbanísticos geométricos. O plano pensado em zonas para a cidade: residencial, comercial e doutrinadores modernistas. No desenvolvimento das ocupações e das decisões políticas e econômicas estes setores se mixaram de alguma forma. Os sujeitos excluídos do mercado imobiliário ocuparam lotes não edificados próximo as indústrias; os sujeitos que possuíam grandes lotes os desmembraram irregularmente e outras áreas; e ainda aqueles que buscaram no distanciamento da cidade a criação de seus loteamentos. A cidade ainda apresenta-se com uma morfologia reconhecível gerada pela separação dos zoneamentos.

Figura 2: Plano Sinop

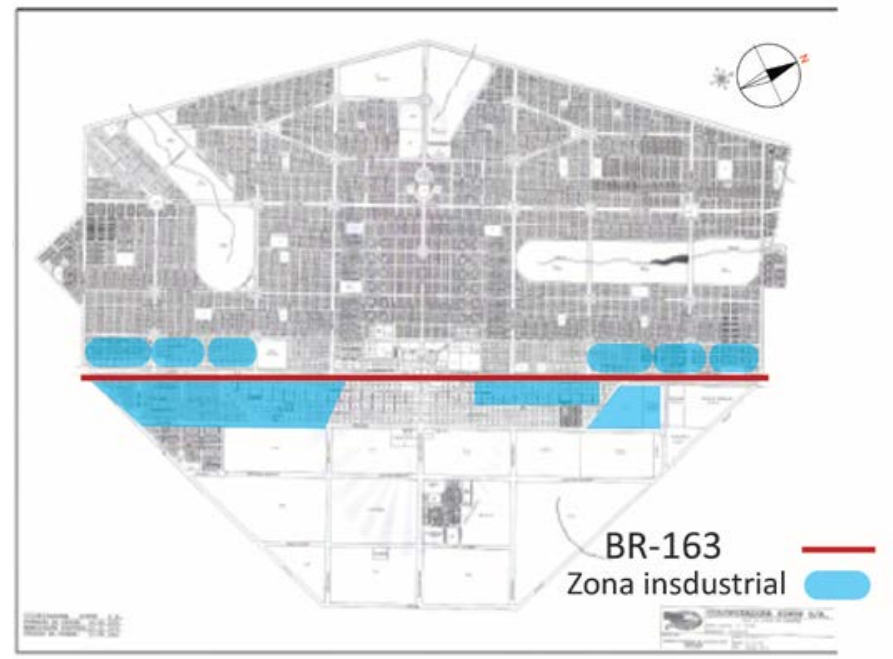

Fonte: Colonizado Sinop 2012, apud RAVACHE, 2013, p.196. Alterações ALMEIDA, 2017.

A figura 2 acima representa este projeto inicial da cidade de Sinop. Destacamos a localização da BR-163, está além de ser determinante para gênese da cidade, constitui-se também como uma divisão socioespacial da mesma. Um lado da rodovia, nordeste encontramos a cidade com melhor infraestrutura, bairros lotes valorizados e do outro lado, sudeste, a cidade para 
operários, migrantes pobre norte e nordeste, nas proximidades da zona industrial. Com a implantação da UFMT na região, existem hoje loteamentos de médio padrão na região também. Outras cidades em MT da BR-163 apresentam em geral esta mesma característica como Sorriso, de dividir a cidade pela BR. Ao tratarmos do tema de divisão ou segregação socioespacial, consideramos importante destacar o que ensina Romancini (2009, p.57) ao elaborar uma síntese do significado de segregação:

De uma maneira geral, os autores que abordam em seus estudos a temática segregação concordam em afirmar que está nada mais é que a manifestação espacial de desigualdades sociais. Seja qual for o motivo que torne um dado espaço urbano melhor que outras áreas da cidade, é para lá que os indivíduos da classe mais abastada com maior prestígio, poder e status vão se agregar. Ainda que não haja atributos naturais especiais, ou mesmo que se localize na periferia da cidade, este espaço será transformado, equipado com infraestrutura e equipamentos públicos que atendam os anseios desta classe social que ali se concentra.

Esta síntese tona-se importante a analisarmos as cidades e notarmos em seus diferentes vetores de expansão e de espaços não edificados é um emaranhado de forças políticas, ideológicas e econômicas.

A equipe de planejamento e fiscalização (PRODEURBS) do município é pequena, conta com 03 (três) arquitetos e 05 (cinco) fiscais nesta área de aprovação de projetos e fiscalizações, existem outros servidores administrativos e de serviços especializados. Esta equipe não conta com uma legislação adequada, o último plano diretor é de 2006, existem alterações parciais nesta legislação. As leis complementares para sua efetivação nunca são aprovadas, os interesses na valorização da terra impedem. O poder público encontra-se desta maneira desarticulado, não contando com recursos humanos, infraestrutura e mesmo as legislações adequadas para cumprir sua função. Entendemos aqui ser de distribuição de justiça social. Hoje a cidade apresenta 177 loteamentos regulares, 10 irregulares e 03 clandestinos, totalizando 190 loteamentos, segundo dados do PRODEURBS de 2017. Existe um esforço para regularização fundiária, muitas vezes após a construção de loteamentos irregulares.

Nos discurso dos moradores e pesquisadores que entrevistamos podemos notar o papel crucial que as imobiliárias exercem na dinâmica de vida das cidades da BR 163 em especial em Sinop. O Prof. Dr. Edison Souza (UNEMAT), se posiciona sobre a questão da expansão da cidade e coloca que a cidade está envolvida prioritariamente para o campo especulação do solo urbano, apresentando forte especulação imobiliária principalmente com a vinda da universidade e dos agronegócios. As observações sobre o número de loteamentos a venda, das revistas com divulgação de lotes e os artigos específicos sobre a região. Podemos concluir o enorme poder e tamanho que o mercado imobiliário de Sinop possui hoje. Estuda-lo se torna então um ponto importante para entendermos a dinâmica da cidade. 
A figura 3 abaixo ilustra como está a distribuição de loteamentos da cidade. Tem apresentado ocupação espacial que não atende a melhor economia da implantação de infraestrutura. Sinop apresenta diversos problemas de infraestrura, o tratamento de esgoto em estações apenas começa com a Estação de Tratamento de Esgoto - ETE Curupy entregue em 2016 e que atende $20 \%$ da população. O resto da cidade tem soluções individuais de tratamento com fossas e sumidouros.

Os novos vetores de ocupação são a região do aeroporto onde são localizados em geral loteamentos de lato poder aquisitivo, nesta área também encontramos a Embrapa e muitas instituições de ensino superior, apenas UFMT é na direção oposta próxima do setor industrial do outro lado da BR. Temos ocupações nas margens da BR 163 também, como o Country Club que é um loteamento de alto padrão há mais de $8 \mathrm{~km}$ da região central da cidade, direção nordeste. E outros loteamentos como o Cidade Alta ${ }^{5}$ que estão em implantação, na direção sudoeste, de média renda. Estes loteamentos não são ali localizados por falta de lotes no setor planejado da cidade, a cidade foi pensada desde o princípio para atender 150.000 habitantes. A implantação de novos loteamentos segue a lógica de valorização imobiliária e de especulação por valorização da terra urbanizada. A professora Rosana Ravache ao estudar algumas das cidades do estado na BR-163 indica que:

Os programas de construção da casa própria, para os cidadãos de baixa renda, como meio de compensar os altos valores cobrados pelos aluguéis, ainda são precários, [...], e excluem um grande número de famílias que necessitam de moradia. Como referência a esta discriminação velada que acontece na maioria das cidades capitaneadas pelo agronegócio em Mato Grosso[...]. (RAVACHE, 2013, p.200)

\footnotetext{
${ }^{5}$ Fonte: https://www.cidadealtasinop.com/. Acesso em 10 out. de 2017.
} 
Revista Nacional de Gerenciamento de Cidades

Figura 3: Loteamento Sinop

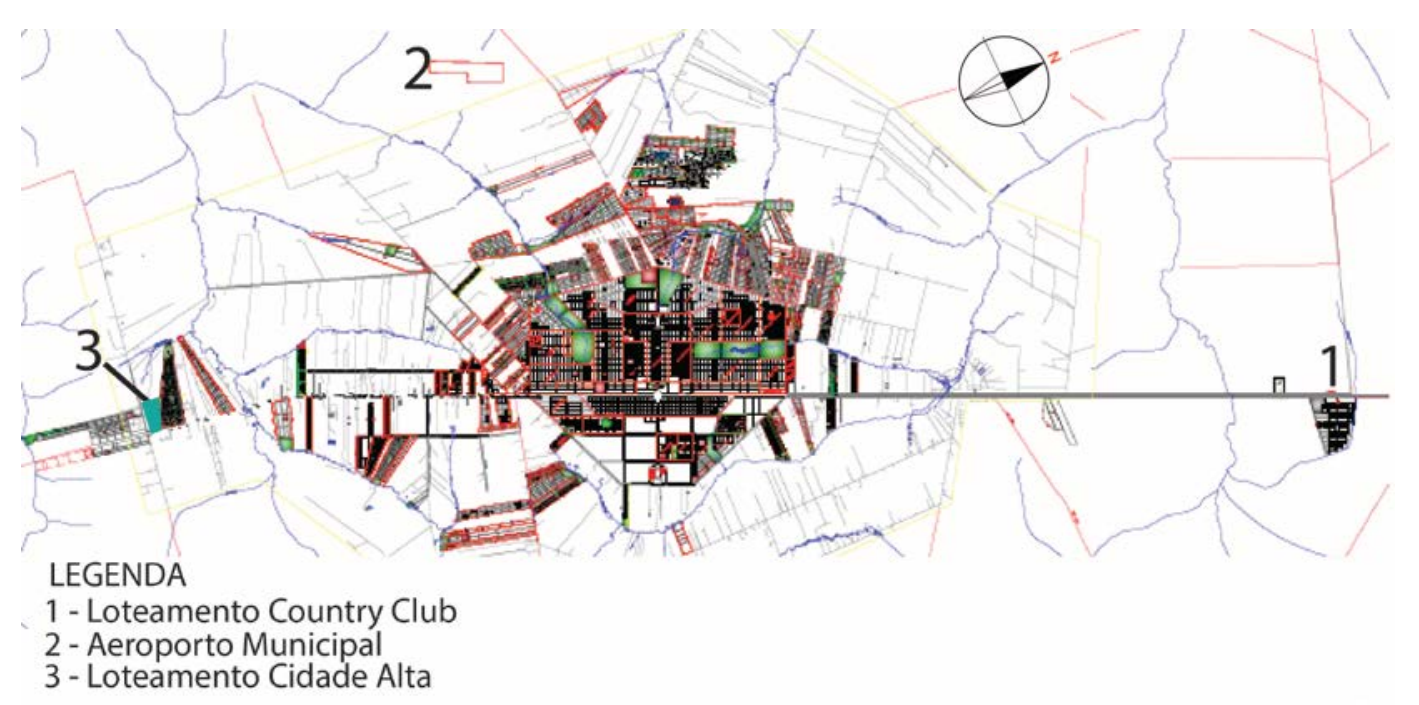

Fonte: Prefeitura de Sinop mapa de 2009, disponibilizado em 2017. Alterações ALMEIDA, 2017.

Esta cidade apresenta um índice de crescimento exorbitante, 13\% entre 2011 e $2015^{6}$, o setor imobiliário está em ascensão, concentra um poder econômico, o que o transforma em um dos principais agentes de produção do espaço da cidade de Sinop. Contudo não atende a todos,. Este processo de loteamento na cidade foi possível graças um conjunto de fatores, ao estudar a cidade Ronaldo Santos diz que:

Isso aconteceu sob a influência do capital subsidiado pelo poder público, acarretando em uma nova organização socioespacial das cidades, motivadas pela especulação imobiliária, onde seus agentes utilizam vários meios para obter lucro sobre o solo urbano, provocando a segregação sócio espacial e impossibilitando as classes de baixo poder aquisitivo de usufruir de espaços bem estruturados. (SANTOS. In ROMANCINI. 2009 ,p. 256)

\section{CONCLUSÃO}

A questão do solo urbanizado em Sinop é muito complexo, a cidade disputa com outros municípios a implantação de diversas empresas, neste processo existe um política de concessão de impostos e terrenos a chama "briga fiscal". A lei municipal no 1.193/2009 de Sinop, permite a doação dos lotes do LIC - Loteamento Industrial, Comercial e de Prestadores de Serviços Norte por parte do munício para empresas. Contudo em 2015 o Ministério Público Estadual entrou

${ }^{6}$ Fonte: População estimada em 135.000 habitantes. https://www.ibge.gov.br/. Acesso em 10 de out de 2017. 
com ação contra esta prática por entender que existe aí um prejuízo ao patrocínio público, decisão preliminar foi acatada pela justiça do Estado.

A cidade apresenta grandes diferenças de condições de vida para seus moradores, com lotes residenciais variando muito de preço começando em $\mathrm{R} \$ 60.000,00$ (sessenta mil reais) no bairro Belo Horizonte até valores de $\mathrm{R} \$ 390.000,00$ (trezentos e noventa mil reais) o condomínio horizontal Cidade Jardim, esta diferença, além da dimensão do lote, está relacionada sua localização social no espaço, bem como de acesso a infraestrutura urbana. Afinal de contas, como já afirmava Guy Debord: "de fato não se mora em um bairro de uma cidade, mas no poder. Se mora em algum lugar da hierarquia" (DEBORD, 1992 apud FELÍCIO, 2007). Embora a cidade apresente um dos melhores IDH do estado 0,754 (IBGE, 2010), temos que reconhecer que que seu crescimento espacial não atende os princípios de melhor eficiência de instalação de infraestrutura, bem como de direito à cidade a todos. Contudo quando consideramos as dimensões do Estado de MT e as precariedades encontradas nos municípios em geral, sem dúvidas a cidade está entre as possui melhor infraestrutura e serviços.

O papel das imobiliárias e dos incorporadores é fundamental, consideramos os principais agentes de negociação do mercado de imóveis, através de acordos com as construtoras, os poderes públicos constituídos, a criação de demanda pela especulação da terra, entre outras estratégias de controle e domínio do solo urbano. Estas ações sobre o solo urbano cria o que alguns estudiosos chamam de "geografia de oportunidades" (CUNHA, 2010). A forma do espaço urbano é uma dimensão da vida social, que vai refletir a estratificação socioeconômica de nossa sociedade. Não existindo acaso no local que se ocupa na cidade e sua condição social.

Torna-se necessário, frente a estes intensos estudos, e nossa legislação - Estatuto da Cidade (2001) - que permite instrumentos de gestão político administrativos para coibir estas práticas uma nova postura frente estas condições. Conhecer os fatores que levam a segregação socioespacial e alinharmos a uma vontade política pode ser um caminho interessante para que as cidades possam apresentar mudanças em seus planos, principalmente cidades jovens como Sinop, que apresentam alta dinâmica econômica e investimentos público e privado.

\section{REFERÊNCIAS BIBLIOGRÁFICAS}

BRASIL. Lei no 10.257, de 10 de julho de 2001: regulamenta os arts. 182 e 183 da Constituição Federal, estabelece diretrizes gerais da política urbana e dá outras providências. Brasília: Congresso Nacional.2001. Disponível em < http://www.planalto.gov.br/ccivil_03/leis/LEIS_2001/L10257.htm>. Acesso em 10 de set. de 2017.

BRASIL. Plano Nacional de Habitação. Ministério das Cidades. Secretaria Nacional de Habitação, 2010. Disponível em <http://bibspi.planejamento.gov.br/bitstream/handle/iditem/285/Publiicacao_PlanHab_Capa.pdf?sequence=1 >. Acesso em jul. de 2017.

CARLOS Ana F. A. Da "organização" à "produção" do espaço no movimento do pensamento geográfico. SPOSITO, Maria E. B.; SOUZA, Marcelo L.; CARLOS, Ana F. A. (Orgs.) A produção do espaço urbano. São Paulo: Contexto, 2011. P. $41-73$

CORRÊA, Roberto Lobato. O Espaço Urbano. São Paulo: Ática, 2002. 
FELíCIO, Erastho. (Org.). Internacional Situacionista. Deriva, pscicogeografia e urbanismo unitário. Ed. Deriva. Porto Alegre:2007.

HARVEY, David. A produção capitalista do espaço. 1a ed. São Paulo: Annblume. 2005.252p.

MACEDO, Fernando Cézar De e RAMOS Pedro. Formação, Expansão e Diversificação Econômica: O Caso do Município Projetado de Sinop/MT. In: Anais do VII Seminário Internacional sobre Desenvolvimento Regional. Santa Cruz do Sul, 2015. Disponível em <http://online.unisc.br/acadnet/anais/index.php/sidr/article/view/13408/2575> Acesso em 04 de abril de 2017.

MOREIRA, R. A Geografia serve para desvendar máscaras sociais. MOREIRA, Ruy(org). Geografia: teoria e crítica. 0 saber posto em questão. Petrópolis: Vozes, 1982.

MOURA, Edenilson Dutra de. Conectando o Urbano e o Ensino Superior: Dinâmicas Espaciais em Sinop - MT. 2015. 274 f. Dissertação (Mestrado em Geografia). Universidade federal de Mato Grosso. Cuiabá, 2015.

MOURA. Edenilson Dutra de. Reflexões urbanas e culturais da cidade de Sinop (MT). Trabalho de Conclusão de Curso de Geografia. Universidade Federal de Mato Grosso. Orientação: Prof.a Drä. Sônia Regina Romancini. Cuiabá, 2013.

NYGAARD, Paul Dieter. Espaço da cidade; segurança urbana e participação popular. Livraria do Arquiteto: Porto Alegre.2010.192 p.

RAVACHE, Rosana Lia. Migração e Modernização em Cidades Médias da Amazônia Legal: Área de Abrangência da BR 163. (Tese Geografia Humana, 2013. Departamento de Geografia da Faculdade de Filosofia, Letras e Ciências Humanas da Universidade de São Paulo,). SÃO PAULO 2013

REVISTA NOTÍ́CIA DO ESTADO DE MATO GROSSO. Sinop. Edição 110. Ano XVIII. Jul.2012

ROMANCINI, Sônia Regina (Org). Novas Territorialidades em Mato Grosso. Cuiabá: EdUFMT, 2009.274p.

ROMANCINI, Sônia R. Reestruturação urbana e novos territórios em Cuiabá. In ROMANCINI, SôniaRegina (Org). Novas Territorialidades em Mato Grosso. EdUFMT, 2009.274p.

ROSSI, Aldo. A Arquitetura da Cidade. 2a ed. São Paulo: Martins Fontes. 2001.309p.

SANTOS, Ronaldo Benedito. A questão Urbana em Sinop-MT: O mercado Imobiliário. In: ROMANCINI, Sônia Regina (Org). Novas Territorialidades em Mato Grosso. Cuiabá: EdUFMT, 2009. P. 255-274.

SILVA, Valdiney Vieira da. Abordagem sobre as políticas públicas e o planejamento urbano na cidade de SINOP MT. 2014. 122 f. Dissertação (Mestrado em Geografia). Universidade Federal de Mato Grosso, Cuiabá, 2014.

SIQUEIRA, Frankes Marcio Batista e NETO, Cornélio Silvano Vilarinho. O Capital Imobiliário e a Cidade - Uma Análise do Espaço Urbano de Cuiabá como Resultado da Preparação a para a Copa do Mundo de 2014. ACTA Geográfica. Boa Vista, v.6, n.13, set./dez. de 2012. pp.137-154

SPOSITO, Maria Encarnação Beltrão e WHITACKER, Arthur Magon (orgs.). Cidade e campo: relações e contradições entre urbano e rural. 2a ed. São Paulo: Expressão Popular, 2010. 